\title{
Intriguing aspects of F-region plasma irregularities revealed by the Gadanki radar observations during the SAFAR campaign
}

\author{
A. K. Patra ${ }^{1}$ and D. V. Phanikumar ${ }^{1, *}$ \\ ${ }^{1}$ National Atmospheric Research Laboratory, Gadanki, India \\ *now at: Korea Astronomy and Space Science Institute, Daejeon, Republic of Korea
}

Received: 13 July 2009 - Accepted: 8 September 2009 - Published: 6 October 2009

\begin{abstract}
Intriguing new results of F-region irregularities observed using the Gadanki MST radar during the SAFAR campaigns, which were conducted during the equinox and summer of 2008 that corresponds to low solar activity condition, are presented. The summer observations are first of its kind from Gadanki. Observations revealed remarkably different morphology of the F-region irregularities in summer when compared to that in equinox. In summer, the F-region irregularities were observed as horizontally stratified structures, while in equinox they were observed as plume structures. Further, the irregularities in summer commenced during the post-midnight hours in contrast to their commencement in the post-sunset hours and occurrence extending to post-midnight hours in equinox. In addition, an intriguing observation of the summer time irregularities is that they occurred when the background electron density was remarkably low as characterized by the disappearance of the F layer trace in the ionograms. An interesting event of equinox that was observed for $10 \mathrm{~h}$ and extended beyond the sunrise time displayed multiple plume structures having periods similar to those of the E-region velocity variations. These observations are discussed with due focus on the genesis of postmidnight F-region irregularities and their possible linkage to the E-region dynamics.
\end{abstract}

Keywords. Ionosphere (Equatorial ionosphere; Ionospheric irregularities)

\section{Introduction}

One of the important components of a newly initiated program named as "Study on Atmospheric Forcing And Responses" (SAFAR) (Jayaraman et al., 2009) is the investiga-

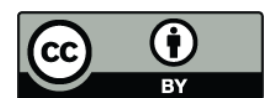

Correspondence to: A. K. Patra (akpatra@narl.gov.in) tion related to the response of the upper mesosphere, lower thermosphere and ionosphere (UMLTI) to the lower and middle atmospheric forcing. The basic intent is to characterize the neutral- and electro-dynamical variabilities in the UMLTI region and various manifestations of plasma instabilities in the E- and F-regions linked with various dynamical forcing of lower and middle atmospheric origin. Since the E-region plasma is strongly coupled with the neutral dynamics, which includes tidal, gravity wave, and planetary-scale winds, the electrodynamics and plasma processes in the E-region are directly influenced by the neutral dynamics. Further, the coupling among various waves makes the region more complex and challenging from both the neutral dynamics and the electrodynamics point of view. In the recent years, the role of various atmospheric wave forcing from lower atmosphere on the F layer plasma distribution and plasma irregularity processes has been well recognized (e.g., Lastovicka, 2006; Immel et al., 2006; Fritts et al., 2008, and the references therein). In this context, the low latitude E-region that connects the equatorial F-region via the magnetic field lines should be considered important due to the possible electrodynamical coupling between the E- and F-regions. To address some of the low latitude processes, as a first step, two pilot campaigns involving the MST radar, lidar, ionosonde, and VHF/GPS scintillations were conducted from Gadanki $\left(13.5^{\circ} \mathrm{N}, 79.2^{\circ} \mathrm{E}, 6.5^{\circ} \mathrm{N}\right.$ mag. lat.), a low latitude station in India, during the March equinox and summer of 2008 to characterize the UMLTI variabilities and plasma irregularities. This paper is meant to present and discuss interesting new results of F-region irregularity structures and dynamics obtained from the Gadanki MST radar observations made during the SAFAR pilot campaigns.

The current understanding on the genesis of F-region plasma irregularities extending to the topside of the F-region relies mainly on the Rayleigh-Taylor (RT) instability. The rapid loss of molecular ions by recombination after the sunset produces a steep vertical plasma density gradient at the

Published by Copernicus Publications on behalf of the European Geosciences Union. 
Table 1. Radar parameters used for studying the F-region irregularities.

\begin{tabular}{ll}
\hline Parameter & Value \\
\hline Frequency & $53 \mathrm{MHz}$ \\
Peak Power-Aperture product & $3 \times 10^{10} \mathrm{~W} \mathrm{~m}^{2}$ \\
Beam (3 dB) & $3^{\circ}$ \\
Beam directions & $15^{\circ} \mathrm{N}$ \\
Receiver bandwidth & $1.7 \mathrm{MHz}$ \\
Inter-pulse Period (IPP) & $5 \mathrm{~ms}$ \\
Pulse width & $16 \mu \mathrm{s}$ \\
No. of FFT points & 256 \\
No. of spectral averaging & 8 \\
Range coverage & $84-684 \mathrm{~km}^{-}$ \\
Range resolution & $2.4 \mathrm{~km}^{-1}$ \\
Nyquist velocity limit & $\pm 283 \mathrm{~m} \mathrm{~s}^{-1}$ \\
Velocity resolution & $2.28 \mathrm{~m} \mathrm{~s}^{-1}$ \\
\hline
\end{tabular}

bottomside of the F-region and the F-region becomes unstable to the RT instability generating plasma bubbles. These plasma bubbles evolve nonlinearly and penetrate into the topside of the F layer. Plasma irregularities responsible for strong spread $\mathrm{F}$ traces in ionograms and scintillations of satellite radio signals are generated during the wake of the plasma bubbles. Plasma irregularities with scale sizes ranging from a few centimeters to a few hundreds of kilometers are generated.

The small-scale (centimeter to a few tens of meters) irregularities are responsible for radar backscatter, which manifest as plumes in radar observations linking the top and bottom of the F-region. It must be stressed that it is Woodman and LaHoz (1976) who, using the radar observations from Jicamarca, proposed for the first time that the F-region plasma irregularities are generated by the RT instability. Since then extensive investigations have been carried out using radar observations to study the height-time distribution of the irregularities, and local time dependence of their occurrence and dynamics, which are linked with sunset terminator and prereversal enhancement of zonal electric field (PRE).

Interestingly, radar observations have also provided enormous amount of evidence that suggested the role of gravity waves as the seed perturbation for the RT instability to grow into plasma bubble (e.g., Roettger, 1973; Kelley et al., 1981; Tsunoda and White, 1981; Hysell et al., 1990; Rao et al., 1997; Patra et al., 2005). Computer simulations of gravity wave seeded RT instability have also successfully reproduced many of the radar observations (e.g., Huang and Kelley, 1996). It is, however, not known how the gravity wave seeds are provided at the bottom of the F layer. Prakash (1999) suggested that seed perturbation of the type of gravity wave could be provided by the low latitude E-region. He suggested that the perturbation electric field associated with gravity wave winds in the E-region could map along the mag- netic field lines to the bottom of the equatorial F-region seeding F-region bubbles. On the other hand, experimental and theoretical studies made in the recent past (Kudeki and Bhattacharyya, 1999; Hysell and Kudeki, 2004; Kudeki et al., 2007) suggested that the shear flow at the bottom of the $F$ layer could generate plasma structures capable of seeding the RT instability. Importantly, the growth rate of the RT instability seeded by such plasma structures is shown to be $14 \mathrm{e}-$ folds larger than its gravity wave counterpart (Kudeki et al., 2007). This mechanism, however, does not account for the long wavelength $(\sim 1000 \mathrm{~km})$ undulation of the bottomside irregularities and plume separation, leaving the role of gravity wave in the physics of F-region irregularity generation to be still important (Kelley et al., 2009).

Investigations have revealed that PRE, which occurs soon after the sunset, plays a crucial role for the growth of the RT instability manifesting plasma bubbles (Fejer et al., 1999; Hysell and Burcham, 2002). The PRE pushes the F layer up and the steep gradient in the bottomside electron density profile after the sunset provides conducive conditions for the RT instability to grow. This quite successfully explains the maximum occurrence of plasma bubble during 20:00-21:00 LT. The decrease in the occurrence of plasma bubble during the later part of the night, except during the magnetically disturbed conditions, is thus understandable considering the fact that the background ionosphere during that time descends, which is not conducive for the growth of the RT instability. Plasma irregularities, however, have been observed in the post-midnight hours by both radio and optical techniques even during geomagnetically quiet conditions. Thus it is not clear at this moment whether the post-midnight F-region irregularities observed during magnetically quiet conditions are freshly generated ones or due to the overhead passage of irregularities generated elsewhere or the reactivation of fossil plasma bubbles.

Two important aspects addressed in this paper are: (1) origin of the required seed perturbations for the generation of the F-region irregularities and their linkage with the Eregion dynamics, and (2) the genesis of post-midnight $\mathrm{F}$ region irregularities. Both of these are poorly understood at this moment. For the second aspect, intriguing new observations of post-midnight F-region irregularities displaying different morphological features, which came from summer campaign, are presented. Notably, the summer observations are the first of its kind from Gadanki and are expected to shed light on the genesis of the post-midnight F-region irregularities.

\section{Radar experiments}

The new observational results presented and discussed in this paper were made using the Gadanki MST radar during the March equinox and summer of 2008. The radar antenna was phased to form the main beam at a zenith angle of $15^{\circ}$ due 


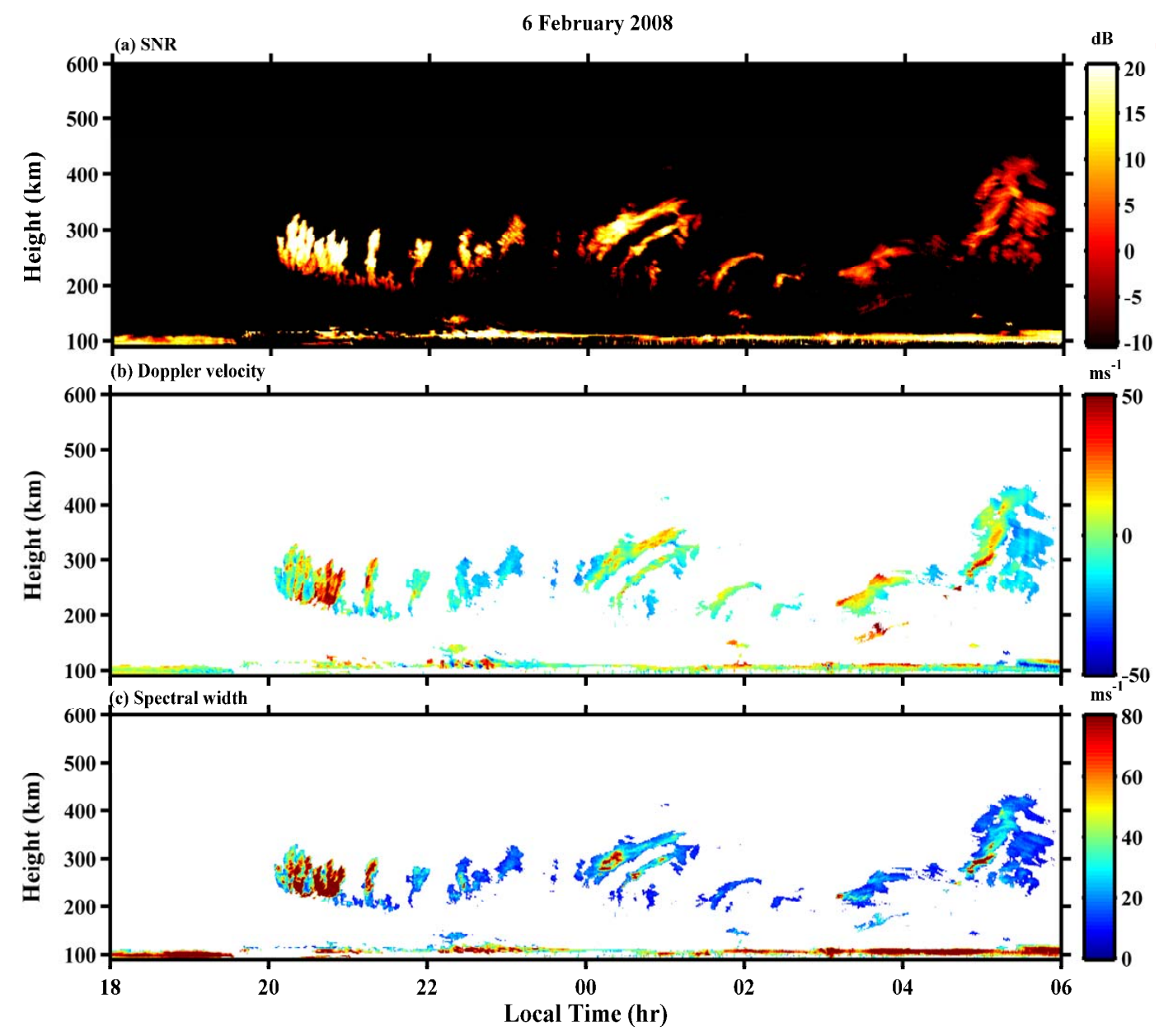

Fig. 1. Height-time variation of (a) SNR, (b) radial Doppler velocity, and (c) spectral width of the E- and F-region echoes observed on 6 February 2008. Positive (negative) velocity represents line-of-sight irregularity motion away from (towards) the radar.

magnetic north. Since Gadanki is a magnetically low latitude station, this beam direction is essential for detecting the F-region echoes arising from the field-aligned electron density irregularities. Other important radar parameters used for the observations are given in Table 1. Radar returns were sampled pulse by pulse and power spectra were computed online using 256 pulse returns. Also, 8 spectra were averaged online before storing the data for post-processing. For the specifications given in Table 1, power spectral data were obtained with range and time resolutions of $2.4 \mathrm{~km}$ and $30 \mathrm{~s}$, respectively. Signal-to-noise ratio (SNR), mean Doppler velocity, and spectral width $(2 \sigma$, where $\sigma$ is the standard deviation of the velocity distribution) were obtained by estimating the three lower order moments. SNR computation was made using noise power reckoned over the entire spectral window of $\pm 283 \mathrm{~m} \mathrm{~s}^{-1}$.

\section{Observational results}

\subsection{Observational overview}

F-region irregularities were observed on 10 nights out of 29 night in the March equinox, while in summer they were observed on all 20 nights of observations. In the equinox, they were observed predominantly in the pre-midnight hours except a few that extended well into the post-midnight hours. Interestingly, F-region irregularities were observed predominantly in the post-midnight hours in summer, except on two events, which commenced at $\sim 22: 00$ LT. It may also be mentioned that no irregularities were observed soon after the sunset during summer unlike those in equinox. Further, an important aspect noted in ionosonde observations (not shown here) during the summer campaign is that no $F$ layer trace was observed during 22:00-05:30 LT. Although similar ionosonde observations were reported earlier by Chandra and Rastogi (1971), radar observations made during those hours are new and intriguing. In the following, three case studies, 

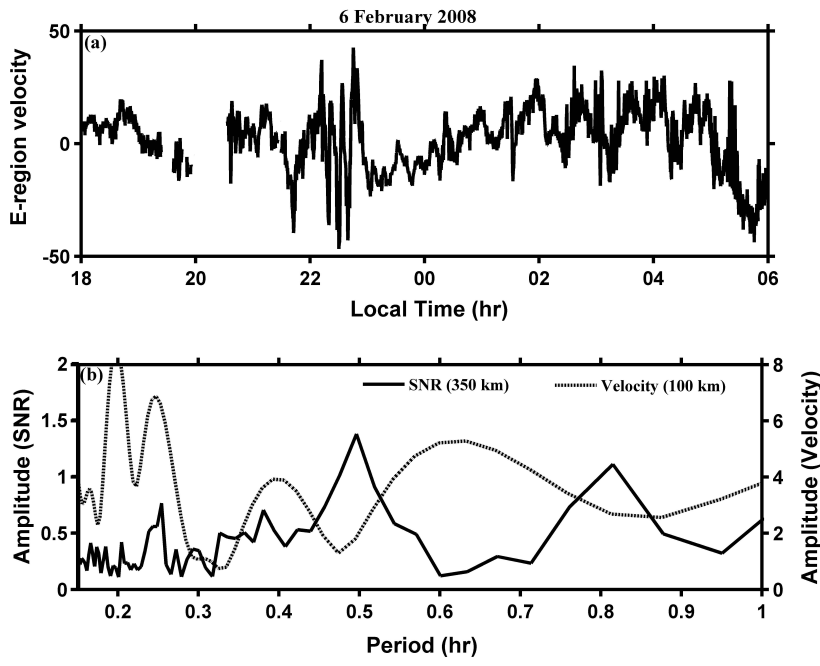

Fig. 2. (a) Line-of-sight Doppler velocities of the E-region echoes observed above $105 \mathrm{~km}$. (b) Amplitude of different periods in the occurrence of plumes (red line) and in the E-region velocities (magenta line).

which correspond to magnetically quite conditions $\left(K_{p}<3\right)$ are presented to illustrate the issues described in the introduction.

\subsection{Equinoxial observations}

Figure 1a-c shows SNR, radial velocity and spectral width of the radar echoes observed on 6 February 2008. The Fregion irregularities commenced soon after the F-region sunset (19:30 LT) and in close coincidence with the local time of occurrence of pre-reversal enhancement of zonal electric field (Hari and Krishnamurthy, 1995). The most striking result of the F-region irregularities observed on this night is the occurrence of periodic plume structures for $10 \mathrm{~h} \mathrm{(20:00-}$ 06:00 LT). The time gaps between two consecutive plumes are between $15 \mathrm{~min}$ and $\sim 1 \mathrm{~h}$. Another important aspect is the periodic descent (during 20:00-22:00 LT and 23:0002:00 LT) and ascent (during 22:00-23:00 LT and 02:0006:00 LT) of the base of the echoing region. Note that a large number of plumes are observed during the descent of the layer consistent with earlier observations made from Gadanki (Patra et al., 2005). Note that the highest altitude plume event occurred after the F-region sunrise (05:10LT) and during the descending phase of the bottomside echoing envelope. Strongest echo (displayed as $\mathrm{SNR}=25 \mathrm{~dB}$ ) was $\sim 40 \mathrm{~dB}$ above the noise (echoes having SNR $\leq-15 \mathrm{~dB}$ are noise) and was observed during 20:00-22:00 LT. It is interesting to note that although the post-sunrise echoes extended to maximum altitude, echo SNR was limited to only $10 \mathrm{~dB}$ (about $15 \mathrm{~dB}$ lower than the strongest signal).

Coming to the radial Doppler velocities, they were in the range of $-25 \mathrm{~m} \mathrm{~s}^{-1}$ to $50 \mathrm{~m} \mathrm{~s}^{-1}$. Positive (negative) veloc- ities represent upward/northward (downward/southward) irregularity motion. Since the echoing region is mostly below $350 \mathrm{~km}$ (where the buoyancy force to the bubble motion can be neglected), the irregularity drift perpendicular to magnetic field in the magnetic meridian plane essentially represents the zonal electric field of $-0.75-1.5 \mathrm{mV} \mathrm{m}^{-1}$. The velocities in the early phase of the event were generally larger than those observed later. For the post-sunset F-region irregularities observed at Gadanki, Patra et al. (2005) reported that the upward/northward Doppler velocities are often $100 \mathrm{~m} \mathrm{~s}^{-1}$ and at times could be as high as $300 \mathrm{~m} \mathrm{~s}^{-1}$. Thus in the present observations, the Doppler velocities were rather small. It is interesting to note that although the plumes were observed for $10 \mathrm{~h}$, the plumes did not extend to altitude higher than $430 \mathrm{~km}$. Note that the Doppler velocities in the plumes occurring during 00:00-02:00 LT and 04:00-06:00 LT, however, are larger than the rest of the structures observed during the post-midnight hours. Since the bubble velocity is a function of electric field and collision frequency (which decreases with height), bubble velocity is expected to be large at higher altitudes. Thus low velocities in low altitude plumes and large velocities in high altitude plumes observed in our observations are consistent with the understanding.

As regard to the spectral widths, they are mostly in the range of $10-100 \mathrm{~m} \mathrm{~s}^{-1}$ and occasionally as high as $200 \mathrm{~m} \mathrm{~s}^{-1}$. Large spectral widths were observed mostly in the initial phase of the event (i.e., during 20:0021:00 LT). After 21:00 LT, the spectral widths are mostly below $30 \mathrm{~m} \mathrm{~s}^{-1}$, except for the two high altitude plume structures, when spectral widths as well as upward/northward velocities are relatively large.

Considering that the E-region over Gadanki is connected to the bottom of the F-region over the magnetic equator through the magnetic field lines, and the observed plumes are representative of the equatorial plasma bubbles mapped to the low latitude via the magnetic field lines, the Doppler velocities of the low latitude E-region assume importance. Also, for the E-region type-2 irregularity velocities above $100 \mathrm{~km}$ altitude observed by the north bearing of the Gadanki radar, Krishnamurthy et al. (1998) have shown that they represent $\boldsymbol{E} \times \boldsymbol{B}$ drift, where $\boldsymbol{E}$ represents zonal electric field. According to Prakash (1999), perturbation electric field from the low latitude E-region, when map to the equatorial Fregion, could provide the seed for the plasma bubble formation. To examine whether the periodic plume structures have any relationship to the E-region perturbation, we present the Doppler velocities of the E-region irregularities observed above $105 \mathrm{~km}$ in Fig. 2a. Noteworthy is the periodic variations in the Doppler velocities (i.e., periodic variation in zonal electric field) throughout the observational run. This observation is intriguing considering that the periodic plumes were also observed throughout the night.

To examine the common periodicities in the plume occurrence and the E-region electric field perturbation, spectral analysis has been performed on the SNR observed at 


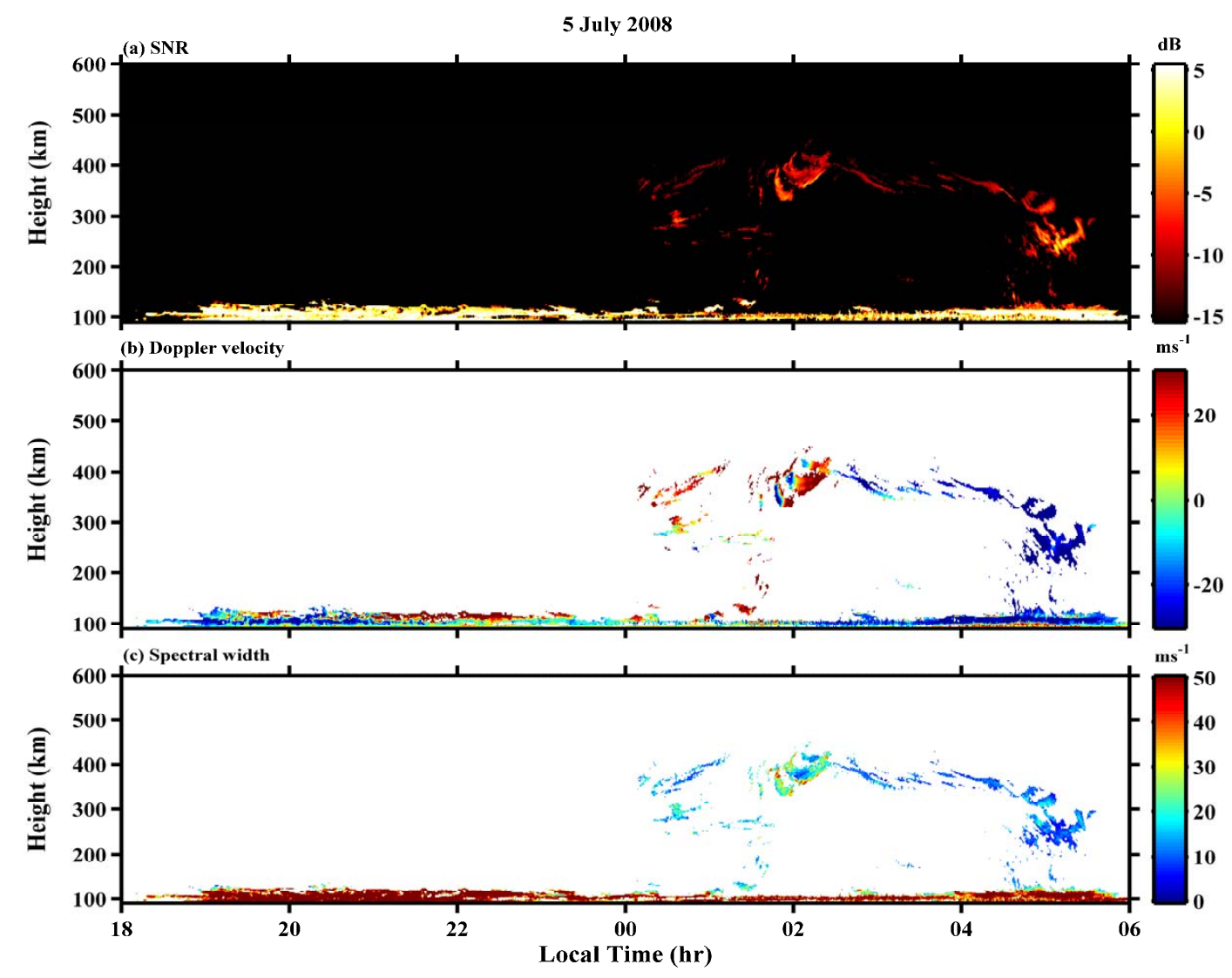

Fig. 3. Same as Fig. 1, but for 5 July 2008. Note that the scales are different from those in Fig. 1.

$300 \mathrm{~km}$ and the E-region irregularity velocities. The results are shown in Fig. 2b. One can clearly see two periods ( $\sim 30 \mathrm{~min}$ and $\sim 50 \mathrm{~min}$ ) dominating in the plume occurrence and the lower periods are less prominent. In the E-region Doppler velocities, significant periods are $35 \mathrm{~min}, 25 \mathrm{~min}$, $15 \mathrm{~min}$ and $10 \mathrm{~min}$. We may recall that $10-15 \mathrm{~min}$ periodicity in Doppler velocity is similar to those observed in the Eregion quasi-periodic (QP) echo occurrence (Venkateswara Rao et al., 2009). The observed common periodicities in both E- and F-regions imply that E-F-region coupling processes may be in place and thus it is quite possible that the F-region structures were related to the plasma bubbles seeded by the E-region (Prakash, 1999). This aspect is discussed in detail later.

\subsection{Summer observations}

In summer, however, the irregularity structures are found to be very different from those shown in Fig. 1. Figure 3a-c shows the radar observations made on 5 July 2008. Echo SNR was limited to $5 \mathrm{~dB}$ and most of the echoes had SNR well below $0 \mathrm{~dB}$. It may be mentioned that a SNR of $-15 \mathrm{~dB}$ represents noisy signal. This implies that these echoes were about $20-25 \mathrm{~dB}$ weaker than their equinoxial counterpart.
However, when compared with the equinoxial post-midnight echoes (for which SNR is $\sim 5 \mathrm{~dB}$ ), they are found to be $\sim 5 \mathrm{~dB}$ weaker than their equinoxial counterpart. The most striking aspect of the SNR map is the morphology of the echoes. The structures show horizontal stratification instead of plumes as observed on 6 February 2008, which display vertical structures occurring discretely as a function of time. The structures observed in summer have close resemblance to the bottom side band structures often observed at the magnetic equatorial location Jicamarca (e.g., Hysell and Burcham, 2002). Also in the initial and final stages of the event, irregularities were observed right from the E-region to the Fregion. It may be stressed that neither of the echo morphologies observed during the post-midnight hours on 6 February and 5 July has commonality.

The Doppler velocities were limited to $\pm 30 \mathrm{~m} \mathrm{~s}^{-1}$ and were upward/northward until 02:30 LT and downward/southward afterwards. It is interesting to note that even during the post-midnight hours, the irregularity velocities were upward/northward, representing the presence of eastward electric field. Further the irregularities in between the E- and F-regions showed upward velocities in the initial stage in association with seemingly ascending irregularity structures and downward/southward velocities at the descending 


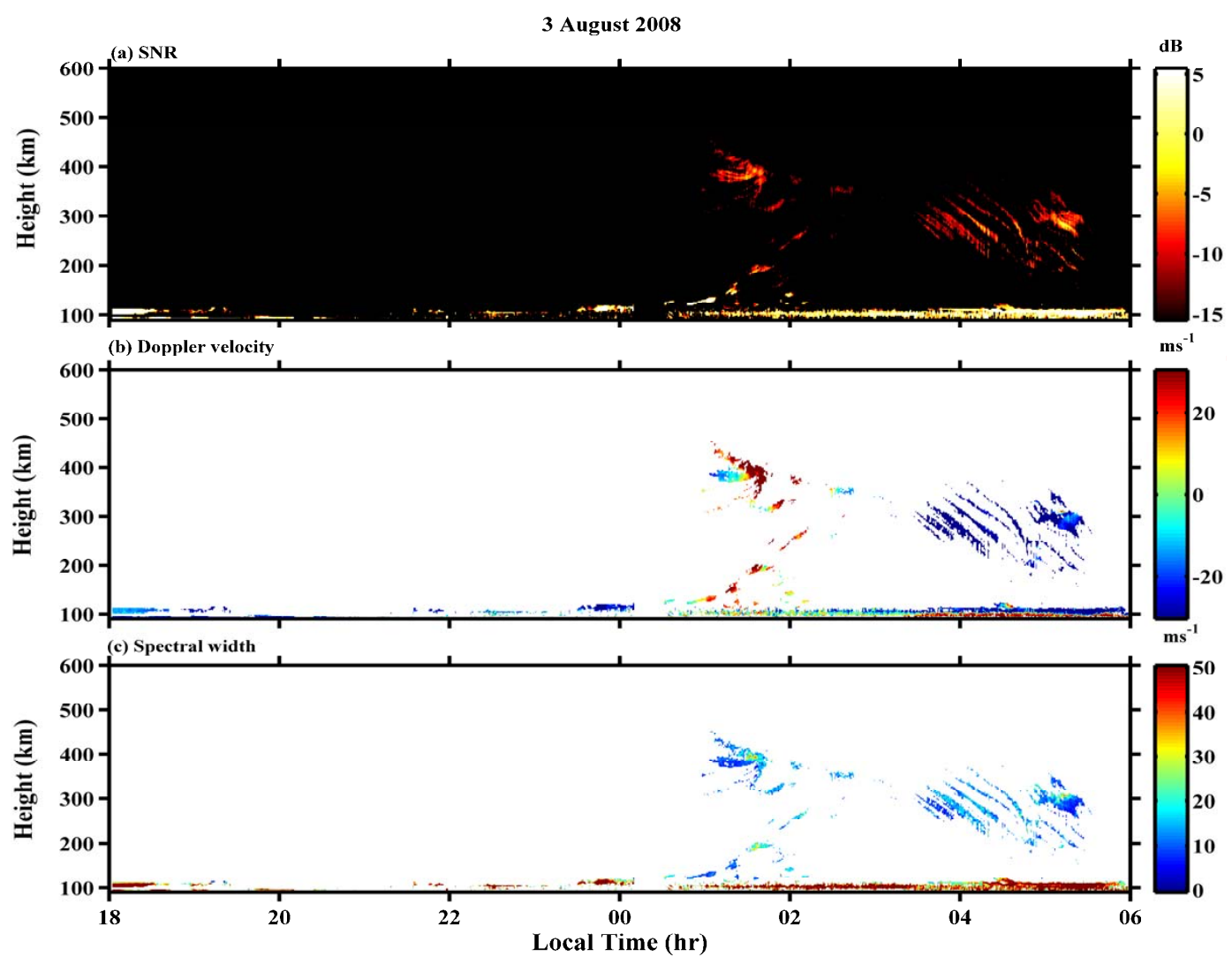

Fig. 4. Same as Fig. 3, but for 3 August 2008.

phase with the descending irregularity structures. Interestingly, the E-region irregularity velocities also showed similar behavior.

As for the spectral widths, they were limited to $30 \mathrm{~m} \mathrm{~s}^{-1}$ and were observed to be somewhat larger prior to $02: 30 \mathrm{LT}$ than those observed later. Although the spectral width values are smaller than their equinoxial counterpart, the decreasing trend in the spectral width with time appears to be very similar to that observed in equinoxial observations.

Figure $4 \mathrm{a}-\mathrm{c}$ shows the observations made on 3 August 2008. In this example also, irregularities appeared in the post-midnight hours. Although the echoing morphology in this case is broadly similar to those of 5 July, the periodic descending striations observed after 03:30 LT are the added features. They resemble closely the E-region quasi-periodic echoing striations (e.g., Venkateswara Rao et al., 2009). In this example also, the irregularities in between E- and Fregions appear to ascend in the initial stage and descend at the final stage.

Doppler velocities in this case also were in the range of $\pm 30 \mathrm{~m} \mathrm{~s}^{-1}$ and upward/northward until 03:00 LT and downward/southward afterwards. The upward/northward and downward/southward velocities again are very much consistent with the seemingly upward motion and downward motion of the irregularity structures, respectively. Spectral widths were limited to $30 \mathrm{~m} \mathrm{~s}^{-1}$ and were observed to be somewhat larger prior to 02:30 LT than those observed later, which are similar to those observed on 5 July 2008.

\section{Discussion}

Firstly, the SAFAR pilot campaign results clearly revealed that the morphology of the F-region irregularities observed in equinox and summer are distinctly different. In equinox, they are observed as plume structures, which are very common in the Gadanki observations and have been reported earlier. In summer, they are observed as horizontally stratified structures instead of plume type structures observed in equinox. Further, in equinox, the F-region irregularities are observed soon after the sunset and the occurrence of plume structures extend to the post-midnight hours at times. In the example shown in this paper, not only the irregularities have been observed during the post-midnight hours but also have been observed after the sunrise. The irregularities in summer, however, have been observed mostly from midnight to sunrise and no echoes have been seen near sunset. Further, their appearance during the absence of $\mathrm{F}$ layer trace in ionograms makes their genesis more curious. 
According to the current understanding, the topside irregularities are accounted for by the RT instability. Sudden height rise of the F layer, which occurs after the sunset due to the action of the PRE, and the steep gradient at the bottom of the F-region provide favorable conditions for the RT instability to take place. It is also assumed that the RT instability requires a seed perturbation. Such instability produces plasma bubbles, which manifest as plumes in the radar observations. While the observations in equinox are consistent with this picture, the observations made in summer are not. Thus question arises whether the irregularities observed in summer are due to the involvement of other processes that remained overlooked. We will discuss this aspect later.

Coming back to the specifics of 6 February 2008 observations, we have two important aspects: (1) common periodicities in the plume occurrence and in the E-region velocity variations, (2) undulation of the bottomside envelope of the echoing region with periods of $\sim 3 \mathrm{~h}$, and (3) occurrence of plumes during the post-midnight hours and beyond the time of sunrise. It may be mentioned that Chandra et al. (1992) observed dominant periodicity of 20 and $67 \mathrm{~min}$ in their VHF scintillation observations from SHAR, a location $110 \mathrm{~km}$ east of Gadanki, which are similar to the plume separations reported here. The common periodicity in the plume occurrence and in the E-region Doppler velocity variations reported here, however, is intriguing since it suggests the possible role of the low latitude E-region electric field perturbation as seed for the growth of the RT instability. Prakash (1999) suggested that electric field perturbation associated with the dynamo action of gravity wave winds in the low latitude Eregion could map to the equatorial F-region seeding the RT instability. Hysell and Kudeki (2004), however, showed that collisional shear instability can give rise to structures that can be seed for the RT instability. The zonal wavelengths of those structures are of the order of $100 \mathrm{~km}$. The question is whether the plume structures were generated due to the seed perturbation coming from the low latitude E-region electric field structures originated by the gravity wave action (Prakash, 1999) or in-situ F-region plasma structures generated by the collisional shear instability (Hysell and Kudeki, 2004). Assuming the zonal plasma drifts to be $100 \mathrm{~m} \mathrm{~s}^{-1}$ (or $50 \mathrm{~m} \mathrm{~s}^{-1}$ ), the observed periods of $15-50 \mathrm{~min}$ translate into horizontal scales of $90-300 \mathrm{~km}$ (or $45-150 \mathrm{~km}$ ). In terms of horizontal scales of the structures, both possibilities exist since some of these structures are of the order of those expected from the shear instability (Hysell and Kudeki, 2004) and also to those which can map from the E-region to the F-region along the magnetic field lines. Thus the key question lies in the fact that whether there existed a shear flow capable of generating plasma structures of the type that manifested multiple plume structures. Although such a possibility is likely, we have no direct proof for it since we have no measurement of the shear flow in the F-region.

Coming to the interpretation of the common periods in our observations, one good possibility is the E-F-region cou- pling. Then, we have two possibilities in front of us: (1) mapping of the E-region electric field structures to the F-region providing seed as proposed by Prakash (1999), and (2) the mapping of the F-region electric field associated with the multiple plume structures, which might have been generated by the RT instability with seed perturbation provided by the collisional shear instability proposed by Hysell and Kudeki (2004), to the E-region. Both possibilities are likely and thus need a careful examination as to what is the cause and what is the effect. In this context, characterization of the low latitude MLT region with due focus to the gravity wave linked variabilities would provide a valuable clue. Well designed experiments in combination with theoretical/simulation works, to be carried out under the SAFAR program, are expected to elucidate this link.

The second important aspect listed is the undulation of the bottomside echoing region with period of $\sim 3 \mathrm{~h}$. If the plasma drift is assumed to be $100 \mathrm{~m} \mathrm{~s}^{-1}$, this time scale translates into horizontal scale of $\sim 1000 \mathrm{~km}$. This scale appears to be compatible with the gravity wave horizontal wavelength. It is interesting to note that the triggering of the first plume at $\sim 20: 00 \mathrm{LT}$ and the high altitude plumes observed at 00:00 LT and 05:00 LT have occurred at the descending phase of the large scale undulated structure in consistence with the gravity wave seeding hypothesis. This means that while the large scale structure seen in the bottomside echoing envelop is a manifestation of gravity wave, the smaller time scale plume structures are due to shorter scale processes. As discussed in the previous paragraph, the short scale structures may be due to the seed structures generated either by shear instability (Hysell and Kudeki, 2004) or the mapping of structured E-region electric field. Based on radar and satellite borne observations, Kelley et al. (2009) came to a conclusion that both gravity waves and shear instabilities need to be considered to account for the different scales of the irregularities. The current observations provide an additional source of perturbation, i.e., the short scale electric field perturbation of gravity wave origin from the low latitude E-region, to this complexity.

The third and an intriguing aspect of the 6 February observations is the extension of plume activity well beyond sunrise. Usually, the irregularities associated with the bubbles that occur after the sunset decay by midnight (e.g., Patra et al., 2004, 2005). The fact that the plume activities continued well beyond the midnight suggests the availability of free energy for the sustenance of the F-region irregularities. Examining the post-midnight observations of radar plumes and airglow observations from Gadanki, Sekar et al. (2007) have shown that the plumes are collocated with the western edges of the depleted regions. They proposed that eastward neutral wind exceeding plasma drift blowing across the western wall of the depleted regions could drive the interchange instability to keep the irregularities sustained during the post-midnight hours. Saito et al. (2008) also arrived at similar conclusion for their post-midnight observations made from Indonesia. 
Radar observations analyzed by Sekar et al. (2007) and Saito et al. (2008), however, were confined to 01:30 LT in the postmidnight. The plumes observed and reported in this paper extended up to 06:00 LT and interestingly the highest altitude plume was observed after the sunrise. After the sunrise, solar photo-ionization is expected to fill up the plasma depletion and reproduce the E-region density that would short circuit the F-region fields, leading to the decay of the irregularities inside the depletion. In this context, a recent experimental investigation based on C/NOFS observations made during 2008 and reported by de La Beaujardiere et al. (2009) is interesting. They provided evidence on the existence of deep plasma depletion during sunrise. Occurrence of plasma depletion during the post-midnight and dawn hours have been observed earlier also, but in association with magnetic storm (e.g., Burke, 1979; Su et al., 2004) and thus it is not surprising considering that eastward electric field associated with magnetic storm can produce such depletion during those structures. The upward/northward velocities in the dawntime plume in our observations clearly indicate the presence of eastward electric field. Further, the spectral width also is relatively large compared to those observed a little earlier, signifying that the bubble must be quite active. Then what made the bubble active during that time? According to Sekar et al. (2007), eastward neutral wind exceeding the plasma drift can be very effective to nurture the decaying/dead bubbles to become re-active. Then if we were to relate the observed eastward electric field with the required eastward neutral wind, we end up in considering a dusk-type of situation of zonal conductivity gradient which occurs during the dawn time so as to be consistent with the observed zonal eastward electric field. This essentially underlines the necessity of simultaneous measurements of plasma and neutral parameters to understand the physical processes responsible for the sustenance of plasma irregularities in the post-midnight hours and after the sunrise.

In this context, the summer observations of the F-region irregularities are interesting and should be considered important. They occurred predominantly in the post-midnight hours and the morphology of the irregularities is very different from those of the equinoxial observations (i.e., plume, which is a close representative of plasma bubble). Earlier studies based on ionosonde observations although showed that the occurrence of F-region irregularities in summer is predominantly a post-midnight phenomenon (e.g., Chandra and Rastogi, 1972; Subbarao and Krishnamurthy, 1994), the radar observations shown here provide additional information on the height time structures of the irregularities. Especially the multilayer thin descending structures are intriguing and indicate the existence of kilometer scale plasma structures. It appears that the structures after their generation were slowly descending and advecting through the radar beam. Having said that they were generated at an earlier time and that time appears to be midnight hours, it is important to identify the free energy and the instability process causing these irregularities during midnight hours.

Subbarao and Krishnamurthy (1994) observed height rise of the F layer prior to their occurrence and suggested that the RT instability is capable of accounting for their generation. Sastri (1999) and Niranjan et al. (2003) advocated the possible role of vertical neutral wind associated with the midnight temperature maximum (MTM) in the RT instability process also. Vertical wind (downward), however, is not the primary parameter. This demands a finite value of eastward electric field during the midnight hours. While during magnetically disturbed conditions such a possibility very much exists, it is generally not expected during quite conditions. The origin of the in-situ F-region eastward electric field during the quiet-time midnight hours for the fresh generation of midnight irregularities, however, is not known. Recently, using C/NOFS observations, de La Beaujardiere et al. (2009) reported high occurrence rate of post-midnight F-region irregularities having no close link with the pre-reversal enhancement of zonal electric field. Their observations also related to the low solar condition of 2008. One good possibility is the mapping of the low latitude E-region electric field generated by neutral dynamics. Since the observations under consideration correspond to local summer when the Es activity is the strongest and prominent structures are seen after 22:00 LT (Venkateswara Rao et al., 2009), such a possibility needs a critical evaluation.

In this context, it may be relevant to consider the midlatitude observations of spread $\mathrm{F}$ in summer. Haldoupis et al. (2003) found that the midlatitude spread F observed in summer were well correlated with the Es activity and proposed that the observed spread $\mathrm{F}$ was the manifestation of $\mathrm{E}$ F-region coupling wherein the electric field associated with the strong Es activity was the driving agent for the F-region becoming unstable. They advocated in favor of the gradient drift instability as the origin of the F-region irregularities. MacDougall et al. (1998) investigated the pre-sunrise Fregion irregularities observed during low solar condition and found that majority of them are associated with the downward bulges on the bottomside F-region and surmised that the irregularities were generated by the gradient drift instability. The fact that the Doppler velocities in the E- and F-regions in summer observations has similar polarity indicates that $\mathrm{E}$ F-region coupling processes is quite likely. Still a question that will linger is- what is the instability process responsible for the post-midnight summer time irregularities? In terms of the RT instability, the morphology of the structures is not very much appealing. The structures appear close to the bottomside structures, which can be accounted for by the gradient drift instability. The upward Doppler velocities (although small) and the stretch of the irregularities from the E- to the F-region in the initial stage of the events, however, are relevant to consider. Also the irregularities extending to the topside indicate the presence of convective process. With the current dataset, it is difficult to arrive at any conclusion as to which mechanism the irregularities are related with. This 
needs a detailed investigation incorporating simultaneous observations of Es activity, and F-region plasma and neutral parameters, a task to be carried out in detail under the SAFAR program.

Acknowledgements. The observations presented in this paper were made under the SAFAR program. The authors whole-heartedly appreciate the MST radar technical staff for making the observations possible.

Topical Editor C. Jacobi thanks H. Chandra and another anonymous referee for their help in evaluating this paper.

\section{References}

Burke, W. J.: Plasma bubbles near the dawn terminator in the topside ionosphere, Planet. Space. Sci., 27, 1187-1193, 1979.

Chandra, H. and Rastogi, R. G.: General features of the ionosphere at Thumba, J. Inst . Telecom. Engrs. 17, 207-216, 1971.

Chandra, H. and Rastogi, R. G.: Spread-F at magnetic equatorial station Thumba, Ann. Geophys., 28, 37-44, 1972.

Chandra, H., Vyas, G. D., Sinha, H. S. S., Misra, R. N., and Prakash, S.: Ionospheric scintillation observations from SHAR, J. Atmos. Terr. Phys., 54, 167-172, 1992.

de La Beaujardiere, Retterer, J. M., Pfaff, R. F., Roddy, P. A., Roth, C., Burke, W. J., Su, Y. J., Kelley, M. C., Ilma, R. R., Wilson, G. R., Gentile, L. C., Hunton, D. E., and Cooke, D. L.: C/NOFS observations of deep plasma depletions at dawn, Geophys. Res. Lett. 36, L00C06, doi:10.1029/2009GL038884, 2009.

Fejer, B. G., Scherliess, L., and De Paula, E. R.: Effects of the vertical plasma drift velocity on the generation and evolution of equatorial spread F, J. Geophys. Res., 104, 19859-19869, 1999.

Fritts, D. C., Vadas, S. L., Riggin, D. M., Abdu, M. A., Batista, I. S., Takahashi, H., Medeiros, A., Kamalabadi, F., Liu, H.-L., Fejer, B. G., and Taylor, M. J.: Gravity wave and tidal influences on equatorial spread $\mathrm{F}$ based on observations during the Spread F Experiment (SpreadFEx), Ann. Geophys., 26, 3235-3252, 2008, http://www.ann-geophys.net/26/3235/2008/.

Haldoupis, C., Kelley, M. C., Hussey, G. C., and Shalimov, S.: Role of unstable sporadic-E layers in the generation of midlatitude spread F, J. Geophys. Res., 108, 1446, doi:10.1029/2003JA009956, 2003.

Hari, S. S. and Krishna Murthy, B. V.: Equatorial night-time Fregion zonal electric fields, Ann. Geophys., 13, 871-878, 1995, http://www.ann-geophys.net/13/871/1995/.

Huang, C.-S. and Kelley, M. C.: Nonlinear evolution of equatorial spread F 2. Gravity wave seeding of the Rayleigh-Taylor instability, J. Geophys. Res., 101, 293-302, 1996.

Hysell, D. L., Kelley, M. C., Swartz, W. E., Farley, D. T., and Woodman, R. F.: Seeding and layering of equatorial spread F by gravity waves, J. Geophys. Res., 95, 17253-17260, 1990.

Hysell, D. L. and Burcham, J. D.: Long term studies of equatorial spread F using the JULIA radar at Jicamarca. J. Atmos. Solar Terr. Phys., 64, 1531-1543, 2002.

Hysell, D. L. and Kudeki, E.: Collisional shear instability in the equatorial F region ionosphere, J. Geophys. Res., 109, A11301, doi:10.1029/2004JA010636, 2004.

Immel, T. J., Sagawa, E., England, S. L., Henderson, S. B., Hagan, M. E., Mende, S. B., Frey, H. U., Swenson, C. M., and Paxton, L. J.: Control of equatorial ionospheric morphology by atmospheric tides, Geophys. Res. Lett., 33, L15108, doi:10.1029/2006GL026161, 2006.

Jayaraman, A., Venkatratnam, M., Patra, A. K., Rao, T. N., Sridharan, S., Rajeevan, M., Gadhavi, H., Kesarkar, A. P., Srinivasulu, P., and Raghunath, K.: Study of Atmospheric Forcing and Responses (SAFAR) campaign: Overview, Ann. Geophys., in review, 2009.

Kelley, M. C., Larsen, M. F., LaHoz, C., and McClure, J. P.: Gravity wave initiation of equatorial spread F: A case study, J. Geophys. Res., 86, 9087-9100, 1981.

Kelley, M. C., Rodrigues, F. S., Makela, J. J., Tsunoda, R. T., Roddy, P. A., Hunton, D. E., Retterer, J. M., de La Beaujardiere, O., de Paula, E. R., and Ilma, R. R.: C/NOFS and radar observations during a convective ionospheric storm event over South America, Geophys. Res. Lett., 36, L00C07, doi:10.1029/2009GL039378, 2009.

Krishnamurthy, B. V., Ravindran, S., Viswanathan, K. S., Subbarao, K. S. V., Patra, A. K., and Rao, P. B.: Small-scale $(\sim 3 \mathrm{~m})$ E region irregularities at and off the magnetic equator, J. Geophys. Res., 103, 20761-20772, 1998.

Kudeki, E. and Bhattacharyya, S.: Postsunset vortex in equatorial F-region plasma drifts and implications for bottomside spread-F, J. Geophys. Res., 104(A12), 28163-28170, 1999.

Kudeki, E., Akgiray, A., Milla, M., Chau, J. L., and Hysell, D. L.: Equatorial spread-F initiation: Post-sunset vortex, thermospheric winds, gravity waves, J. Atmos. Solar-Terr. Phys., 69, 2416-2427, 2007.

Lastovicka, J.: Forcing of the ionosphere by waves from below, J. Atmos. Sol.-Terr. Phys., 68, 479-497, 2006.

MacDougall, J. W., Abdu, M. A., Jayachandran, P. T., Cecile, J.-F., and Batista, I. S.: Presunrise spread F at Fortaleza, J. Geophys. Res., 103, 23415-23425, 1998.

Niranjan, K., Brahmanandam, P. S., Ramakrishna Rao, P., Uma, G., Prasad, D. S. V. V. D., and Rama Rao, P. V. S.: Post midnight spread-F occurrence over Waltair $\left(17.7^{\circ} \mathrm{N}, 83.3^{\circ} \mathrm{E}\right)$ during low and ascending phases of solar activity, Ann. Geophys., 21, 745750, 2003, http://www.ann-geophys.net/21/745/2003/.

Patra, A. K., Sripathi, S., and Tiwari, D.: Coupling effect of the equatorial $\mathrm{F}$ region irregularities on the low latitude $\mathrm{E}$ region instability processes, Geophys. Res. Lett., 31, L17803, doi:10.1029/2004GL020486, 2004.

Patra, A. K., Tiwari, D., Sripathi, S., Rao, P. B., Sridharan, R., Devasia, C. V., Viswanathan, K. S., Subbarao, K. S. V., Sekar, R., and Kherani, E. A.: Simultaneous radar observations of meter-scale F region irregularities at and off the magnetic equator over India, J. Geophys. Res., 110, A02307, doi:10.1029/2004JA010565, 2005.

Prakash, S.: Production of electric field perturbations by gravity wave winds in the $\mathrm{E}$ region suitable for initiating equatorial spread F, J. Geophys. Res., 104, 10051-10069, 1999.

Rao, P. B., Patra, A. K., Sarma, T. V. C., Krishnamurthy, B. V., Subbarao, K. S. V., and Hari, S. S.: Radar observations of updrafting and downdrafting plasma depletions associated with the equatorial spread F, Radio Sci., 32, 1215-1227, 1997.

Roettger, J.: Wavelike structures of large scale equatorial spread F irregularities, J. Atmos. Terr. Phys., 35, 1195-1206, 1973.

Saito, S., Fukao, S., Yamamoto, M., Otsuka, Y., and Maruyama, T.: Decay of 3-m scale ionospheric irregularities associated with a plasma bubble with the Equatorial Atmosphere Radar, J. Geo- 
phys. Res., 113, A11318, doi:1029/2008JA013118, 2008.

Sastri, J. H.: Post-midnight onset of spread-F at Kodaikanal during the June solstice of solar minimum, Ann. Geophys., 17, 11111115, 1999, http://www.ann-geophys.net/17/1111/1999/.

Sekar, R., Chakrabarty, D., Sarkhel, S., Patra, A. K., Devasia, C. V., and Kelley, M. C.: Identification of active fossil bubbles based on coordinated VHF radar and airglow measurements, Ann. Geophys., 25, 2099-2102, 2007, http://www.ann-geophys.net/25/2099/2007/.

Su, S.-Y., Yeh, H. C., Chao, C. K., and Heelis, R. A.: Supercooled ion temperatures observed in the topside ionosphere at dawn median during storm periods, J. Geophys. Res., 109, A06307, doi:10.1029/2003JA010139, 2004.
Subbarao, K. S. V. and Krishna Murthy, B. V.: Seasonal variations of equatorial spread-F, Ann. Geophys., 12, 33-39, 1994, http://www.ann-geophys.net/12/33/1994/.

Tsunoda, R. T. and White, B. R.: On the generation and growth of equatorial backscatter plumes -1 . Wave structure in the bottomside F layer, J. Geophys. Res., 86, 3610-3616, 1981.

Venkateswara Rao, N., Patra, A. K., Pant, T. K., and Rao, S. V. B.: Morphology and seasonal characteristics of low latitude E region quasi-periodic echoes studied using large database of Gadanki radar observations, J. Geophys. Res., 113, A07312, doi:10.1029/2007JA012830, 2009.

Woodman, R. F. and LaHoz, C.: Radar observations of F region equatorial irregularities, J. Geophys. Res., 81, 5447-5466, 1976. 